\title{
Tactical and operational management of wind energy systems with storage using a probabilistic forecast of the energy resource
}

\author{
Cristina Azcárate ${ }^{\text {a }}$, Fermín Mallor ${ }^{\text {a, * }}$, Pedro Mateo ${ }^{\text {b }}$ \\ a Public University of Navarre, 31006 Pamplona, Spain \\ ${ }^{\mathrm{b}}$ University of Zaragoza, 50009 Zaragoza, Spain
}

\section{A R T I C L E IN F O}

\section{Article history:}

Received 31 March 2016

Received in revised form 31 August

2016

Accepted 30 October 2016

Available online $\mathrm{xxx}$

Keywords:

Renewable energy

Energy storage

Management policy

Stochastic optimization

Tactical and operational policies

\section{A B S T R A C T}

The storage of energy facilitates the management of renewable energy systems by reducing the mismatch between the supplied energy and the forecasted production due to forecasting errors. The storage increases the reliability of the renewable energy system and enables participation in the electricity market by committing to the sale of electricity for the following day. Nevertheless, the inclusion of the energy storage capacity requires the development of new management policies. In this paper, we propose a management strategy for a renewable energy system with storage capacity that integrates tactical and operational decisions in a single mathematical model that makes use of an updated probabilistic wind speed forecast. Management policies are obtained by solving a sequence of rolling-horizon stochastic optimization problems whose formulation is inspired by the Stochastic Approximation Average technique. The management policies are illustrated by their application to wind-farms using hydrogen as the energy storage medium.

(C) 2016 Published by Elsevier Ltd.

\section{Nomenclature}

$C_{c_{i}}$

$C_{p_{i}}$

$C_{s_{i}}$

Cap Recovery

Cap $_{\text {Tank }}$

Captransf

$d_{i}^{-}$

$d_{i}^{+}$

$d_{i j}^{-}$

$d_{i j}^{+}$

\section{$E$ [.]}

EfI

EfO

$G_{i}$ unit price of committed energy at hour $i$

unit penalty cost of not supplying committed energy at hour $i$

unit price of surplus energy at hour $i$ maximum capacity of the recovery process $(H 2 \rightarrow k W h)$

maximum storage capacity of the tank

maximum capacity of the transformation $\operatorname{process}(k W h \rightarrow H 2)$

negative deviation of the supplied energy with regard to the commitments

positive deviation of the supplied energy with regard to the commitments

negative deviation of the supplied energy with regard to the commitments associated with the predicted wind speed curve $w_{j}(t)$

positive deviation of the supplied energy with regard to the commitments associated with the predicted wind speed curve $w_{j}(t)$

expected value of expression[.]

efficiency rates of the transformation process

efficiency rates of the recovery process

$k W h$ generated at hour $i$

\footnotetext{
* Corresponding author.
}

Email addresses: cazcarate@unavarra.es (C. Azcárate); mallor@unavarra.es (F. Mallor); mateo@unizar.es (P. Mateo)
$G_{i j}$

PWSF

$Q_{i}$

$T_{i}$

$T_{i j}$

$w_{j}(t)$

$W(t)$

$X_{i}^{I}$

$X_{i}^{I}$

$X_{i}^{O}$

$X_{i}^{O}$

$Y_{i}$

$Z_{i}$

$Z_{i j}$ $k W h$ generated at hour $i$ associated with the predicted wind speed curve $w_{j}(t)$ probabilistic wind speed forecast stochastic part of the economical objective function that includes the penalty and surplus cost

$k W h$ stored in the tank at hour $i$

$k W h$ stored in the tank at hour $i$ associated with the predicted curve $w_{j}(t)$

wind speed for time $t$ from the $j$-th prediction curve probabilistic wind speed forecast at time $t$

$k W h$ transformed into $\mathrm{H} 2$ and stored in the tank

$k W h$ transformed into $\mathrm{H} 2$ and stored in the tank, at time $i$, associated with $w_{j}(t)$

$k W h$ obtained transforming $\mathrm{H} 2$ from the tank, at time $i$, into electricity (recovery process)

$k W h$ recovered from the tank, at time $i$, associated with the predicted curve $w_{j}(t)$

$k W h$ committed for selling at hour $i$

$k W h$ sold at hour $i$

$k W h$ sold at hour $i$ associated with the predicted wind speed curve $w_{j}(t)$

\section{Introduction}

Renewable energy provides valuable benefits to the environment, public health, and the economy, but it has some drawbacks that increase the difficulty of its management. The high variability in its availability and uncertainty in its forecasting hinders the matching of production to demand. Consequently, when there is low renewable energy production in geographic areas with high renewable energy 
penetration, it is necessary to employ energy produced from fossil fuels to support the network. Fig. 1 illustrates this situation in the case of Spain where, on average, more than one third of the electricity is produced by renewable sources; however, although there are periods in which the renewable penetration reaches $70 \%$, in others, it does not reach $20 \%$. These periods with a lack of renewable energy generation are compensated for by a greater generation of energy from unclean sources, mainly from coal power plants.
The storage of energy would enable the management of the generated renewable energy, diminishing the effects of forecasting errors by matching the output energy to the forecasted production. Thus, the reliability of the renewable energy system would increase and the storage would enable participation in the electricity market by committing to the sale of electricity for the following day. Furthermore, the storage of energy during the high production periods and its release during the low production periods would help to increase the renewable energy penetration index. The storage of energy refers to the
Source: REE

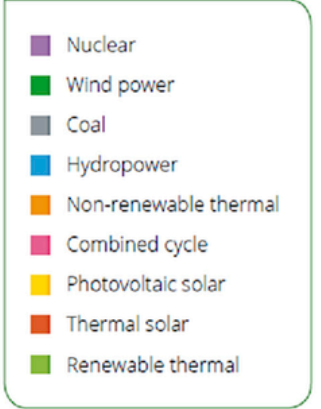

Demand coverage 2014, in Spain

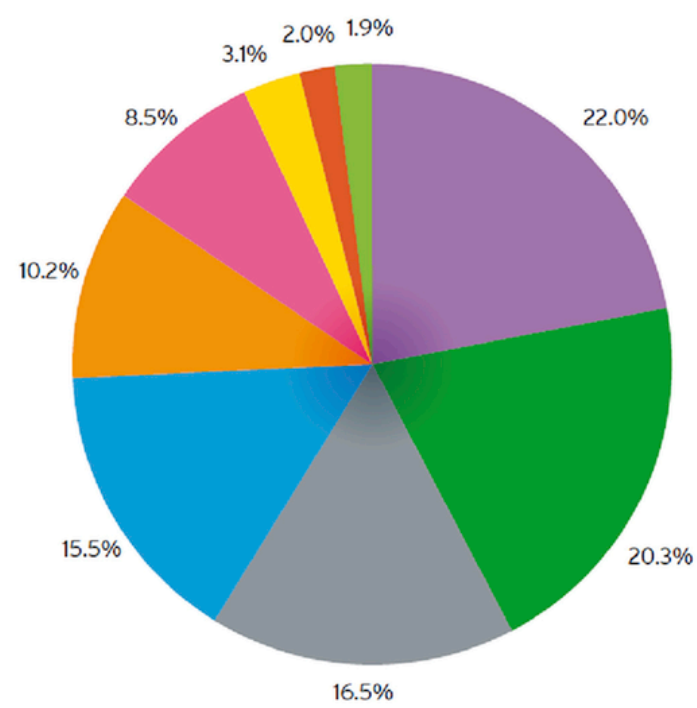

Percent

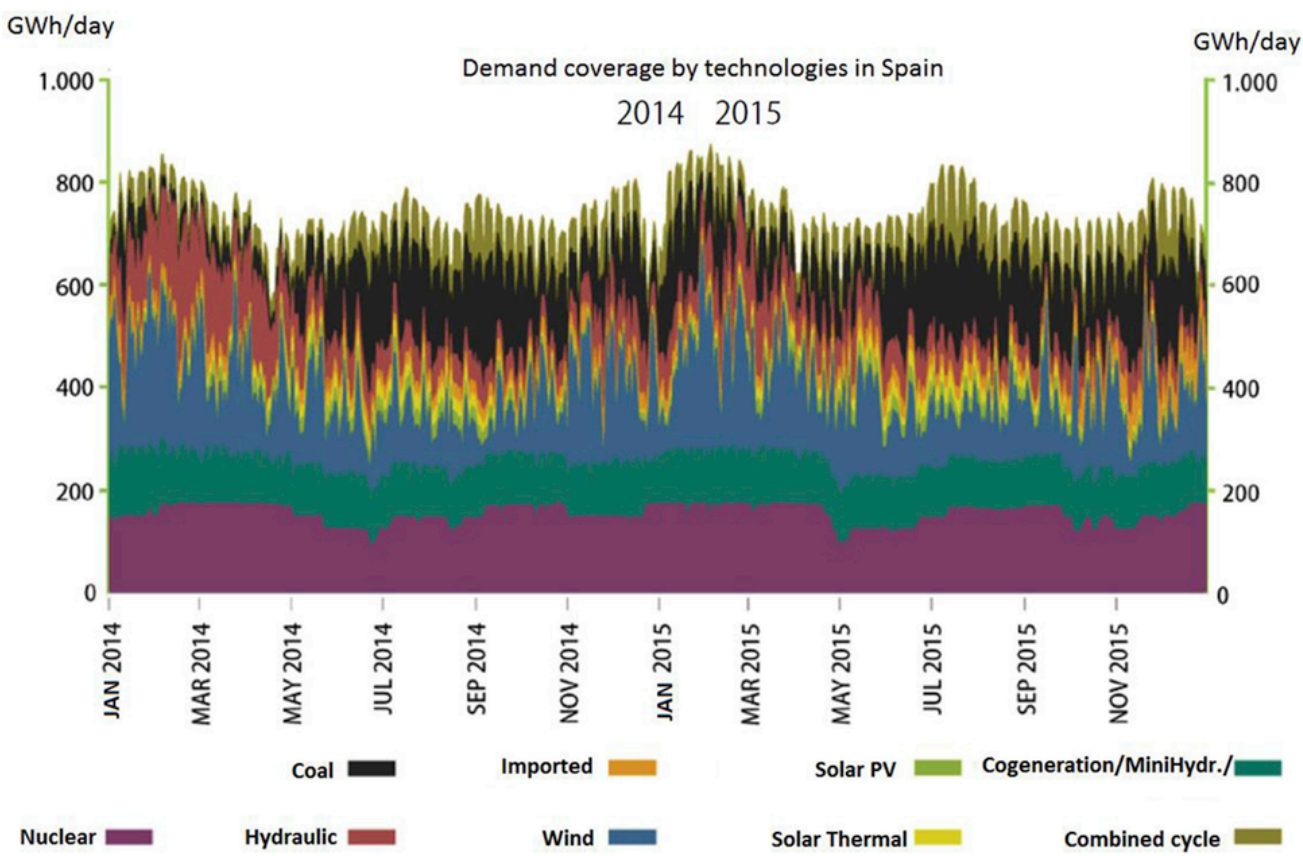

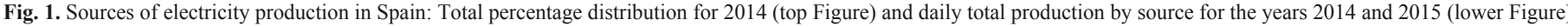
(Source REE: http://www.ree.es/en). 
process of converting energy from one form, usually electrical energy, to a storable form in order to convert the stored energy back into electrical energy when needed. According to the multiple functions of the energy storage many authors have reviewed in the specialized literature research results from different perspectives: new materials, new technologies, management, applications, etc. (see for example [3], [7] [14]). A comprehensive critical review of several types of storage technologies and their deployment status is provided in Ref. [5]. In addition to the state of the art of the available technologies, Luo et al. provide an application potential analysis and where they would be suited for integration into a power generation and distribution system, [16].

This paper is focused on wind energy, and among the several energy storage systems available (lead-acid and sodium-sulfur batteries, compressed air energy storage, pumped hydroelectric storage, electrolysis combined with fuel cells, etc.), hydrogen (H2) is considered as the storage medium. See Refs. [6] and [29] for a review of energy storage technologies for wind power applications, and see Refs. [4] [10], and [15] for different perspectives on the integration of storage technologies. Water electrolysis technology produces hydrogen which can be stored in high pressure containers. The stored hydrogen is used for electricity generation by means of fuel cell, which can convert the hydrogen plus oxygen in water plus energy $\left(2 \mathrm{H} \_2+\mathrm{O} \_2 \rightarrow 2 \mathrm{H} \_2\right.$ $\mathrm{O}+$ Energy). It is a flexible way to store renewable energy on a large, long-term scale potential from $1 \mathrm{~kW}$ to hundreds of MW, [22]. Hydrogen has the largest energy content of any fuel, with a capacity to hold $120 \mathrm{MJ} / \mathrm{kg}$, so that small amount of hydrogen can store significant amounts of energy. The stable chemistry of hydrogen also facilitates the storage of energy longer than any other medium.

Nevertheless, the analysis presented in this paper could be easily adapted to other storage systems and even to other renewable sources of energy. A hybrid wind-hydrogen energy system comprises electricity-generating wind turbines, electrolyzers, and hydrogen com- pressors to convert electricity into hydrogen (the conversion process), an H2-tank with finite hydrogen storage capacity, and various energy-conversion technologies for the process of turning hydrogen into electricity (the recovery process) [1].

Energy prices follow rules similar to those of the stock market. They vary with demand and depend of the availability of the different energy sources. They fluctuate throughout a given day (as illustrated in Fig. 2) and vary for the same time on different days and among different periods of the year (as reflected by the data in Table 1, which summarizes information from the Spanish electricity market in 2015). Our price model is taken from the Iberian Market, which is one of Europe's more liquid ones. There is a detailed description of the electricity market on the web page of OMIE ([30]), the company that manages the wholesale electricity market on the Iberian Peninsula. Electricity prices in Europe are set every day at 12 noon for the subsequent $24 \mathrm{~h}$ period. The purpose of this daily market is to facilitate electricity transactions for the following day through the presentation of electricity sale and purchase bids by the market participants. Furthermore, prices depend on whether the amount of electricity to be sold has been pre-committed the previous day. In the case of a pre-commitment, the price is higher, but if the agreed amount is ultimately not supplied, then a penalty must be paid. When more than the agreed amount is supplied, the surplus has a lower price. Thus, to obtain the full benefit of participation in the electricity market, it is necessary to commit the maximum possible amount of electricity for the day ahead and to have no deviations in the quantity of electricity ultimately supplied.

The drawback of this system for determining electricity rates for wind energy is that the exact amount of energy that will be produced in the future cannot be known in advance because of the stochastic nature of the wind. Therefore, the commitments to supply energy in the electricity market must be made based on wind speed forecasts whose errors will negatively impact the management of the energy

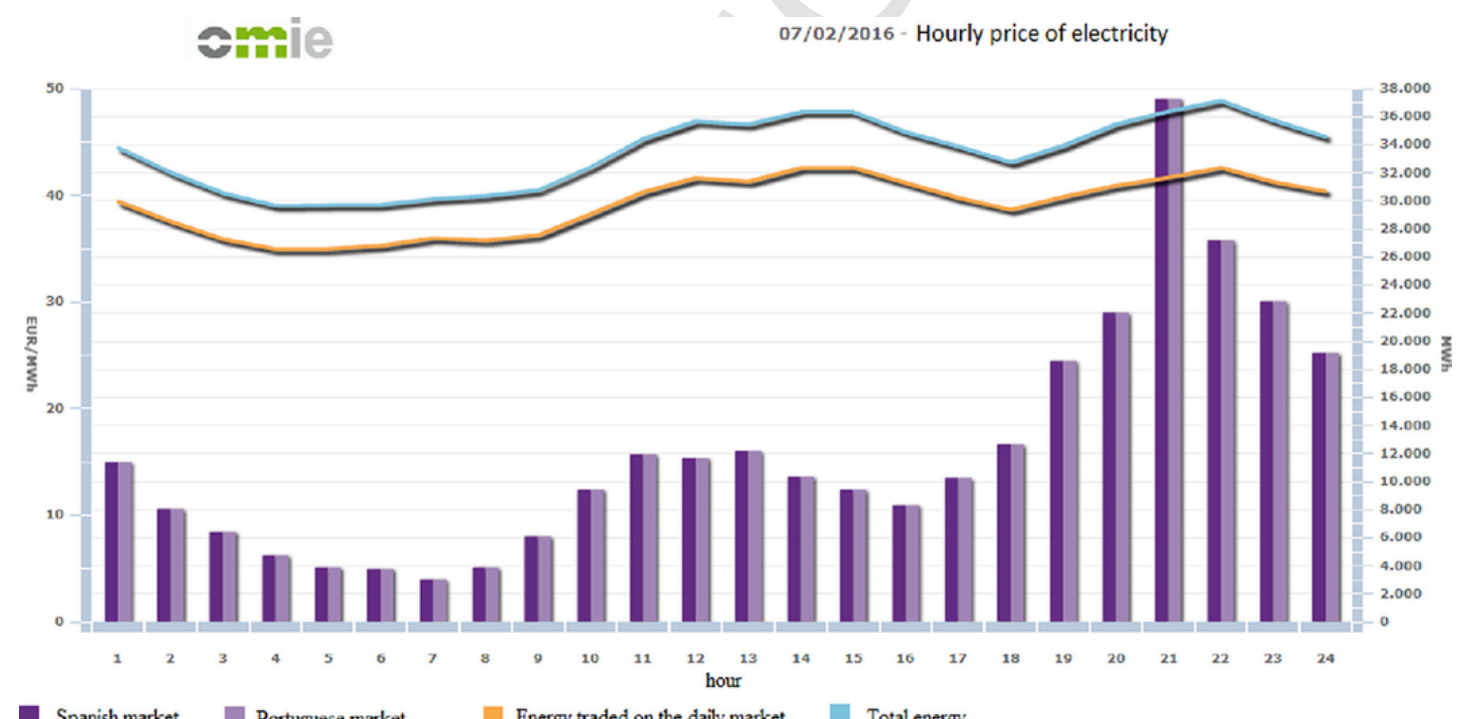

Fig. 2. Example of the variation in the hourly electricity price for the Iberian Peninsula. Source: OMIE web page: http://www.omie.es/en/inicio.

Table 1

Relevant data from the Spanish electricity market for 2015. Source: OMIE web page: http://www.omie.es/en/inicio.

\begin{tabular}{|c|c|c|c|c|c|c|c|c|}
\hline & Hour max. & Hour min. & Max. daily difference & Min. daily difference & Max. daily average & Min. daily average & Max. monthly average & Min. monthly average \\
\hline$€ / \mathrm{MWh}$ & 85.05 & 4.0 & 65.15 & 6.07 & 66.41 & 16.35 & 59.55 & 42.57 \\
\hline
\end{tabular}


system. Usually, the magnitude of the forecasting error grows with increasing forecast lead time.

The prevailing paradigm in weather forecasting, in general, and in the wind speed forecast, in particular, is to issue deterministic forecasts based on numerical weather prediction models [28]. These models describe the dynamic and physical behaviors of the atmosphere and are usually run under different initial conditions. Each model, run under different initial conditions, generates a trajectory that forecasts the future wind speed values. A probabilistic wind speed forecast (PWSF) at time $t$ is a set of $m$ predicted wind speed trajectories for the near future [20]. Usually, meteorological forecasts have a forecast resolution

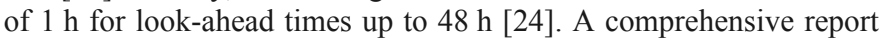
on numerical weather prediction has been issued by Argonne National Laboratory [21]. Ensemble forecasting methodologies enable to estimate the probability distribution of future wind speed variables [9].

Nevertheless, as is recognized in Ref. [25], a number of decision support systems using PWSF as an input need ensembles (in other words, trajectories) instead of predictive densities. For example, in Ref. [19], forecasted wind speed trajectories are simulated by adding random samples drawn from ARMA series modeling possible outcomes of forecasting errors to historical time series. These trajectories are fed into a stochastic linear programming model to schedule the electricity production from different sources of energy in cases of high wind energy penetration.

This paper is focused on obtaining both tactical and operational management policies for wind farms equipped with energy storage systems. By tactical decisions, we mean the decisions made every day to fix the amount of energy that should be committed for selling for each of the $24 \mathrm{~h}$ of the day ahead. The information available for these decisions consists of the electricity prices, the associated penalties, the state of the energy storage, the commitments to sell electricity for the rest of the day, and a PWSF. Operational decisions are made every hour when the amount of electricity to sell must be decided. These operational decisions are made taking into account the produced and committed electricity for the current hour and the state of the energy storage, as well as the commitments and the wind speed forecast for the near future and the electricity prices. These operational and tactical decisions, in the presence of a PWSF, have been treated separately in the literature. In this stochastic environment, the decisions of commitments, including how the system will be operated in the future, and the operational decisions, considering the future commitments, have not yet been studied simultaneously. In Ref. [1] a mixed integer linear program problem was proposed to obtain the commitments using only one trajectory for the wind forecast [2]. introduced a newsvendor strategy for fixing the commitments making use of a PWSF. Operational decisions were not optimized in either of these two models, which consider only simple strategies oriented towards fitting the committed energy as much as possible. Certain types of optimal policies for the management of the energy tank were studied in Ref. [18], but the commitments are fixed independently of these operational strategies. Using the future production densities obtained from a PWSF, an operational strategy for the management of a set of batteries connected to a wind-farm is proposed in Ref. [12] to control the deviations from the dispatch curve.

In this study, we present a unique stochastic mathematical model that is used to obtain both the commitments of energy and the operational management of the energy system. When this integrated model is applied to obtain one type of decision, it also considers the other type of decision. Furthermore, the use of this mathematical model in a rolling horizon strategy includes a regular updating of the PWSF.
To obtain both optimal management policies, we formulate and solve a sequence of rolling-horizon stochastic optimization problems whose formulation is inspired by the Stochastic Approximation Average (SAA) technique ([11] [27]).

The paper is organized as follows. In section 2, we describe the energy system management and we present its mathematical modeling in a stochastic environment. We propose an SAA inspired algorithm to solve it. Section 3 illustrates the methodology by analyzing several scenarios defined by differences in the variability in the wind regime, different electricity prices and differences in the accuracy of the wind speed forecasts. Furthermore, we compare the results of this method with one that separately optimizes both types of decisions. Finally, section 4 contains our conclusions and final remarks.

\section{Mathematical modelling}

\subsection{Stochastic nature of the energy system management}

We consider a wind energy system grid-connected to a storage capability. In particular, we assume that the energy is stored by producing $\mathrm{H} 2$ in an electrolysis process, although other storage systems could also be considered. This energy backup facilitates participation in the electricity market through committing energy to be sold for the day ahead. These commitments are made once per day and can be considered as tactical decisions. In the day-ahead electricity market, the suppliers of energy must declare the amount of energy that they are selling in each one of the $24 \mathrm{~h}$ of the following day. Specifically, let $Y_{i}$ be the amount of $k W h$ committed for selling at hour $i$. The revenue obtained from the selling of $Y_{i} k W h$ at hour $i$ is $C_{c_{i}} Y_{i}$, where $C_{c_{i}}$ is the unit price of a committed $\mathrm{kWh}$ at hour $i$. Let $Z_{i}$ be the amount of $k W h$ ultimately sold at hour $i$. In general, it is advantageous to match the amount of committed energy $Y_{i}$ with the dumped energy $Z_{i}$ because deviations have adverse economic consequences: when the sold energy $Z_{i}$ is less than $Y_{i}$, a penalty $C_{p i}$ should be paid for each $k W h$ committed and not supplied (furthermore, the renewable energy system becomes a non-reliable energy supplier). For the case in which the sold energy $Z_{i}$ exceeds the committed energy $Y_{i}$, the selling price of each $k W h$ in excess, $C_{s_{i}}$, is less than the committed $k W h$ price, $C_{c_{i}}$ . Thus, the total economic revenue at hour $i$ with $Y_{i}$ committed $K W h$ and $Z_{i} k W h$ sold can be expressed as:

$$
C_{c_{i}} Y_{i}+C_{s_{i}} d_{i}^{+}-\left(C_{c_{i}}+C_{p_{i}}\right) d_{i}^{-}
$$

where. $Z_{i}+d_{i}^{-}-d_{i}^{+}=Y_{i}, \quad$ with $d_{i}^{-}, d_{i}^{+} \geq 0$

Here, the deviational variables $d_{i}^{-}$and $d_{i}^{+}$express the negative and positive deviations of the supplied energy with regard to the commitments.

The sold energy $Z_{i}$ comes from the $G_{i} k W h$ generated at hour $i$ plus the $X_{i}^{O} k W h$ obtained transforming $\mathrm{H} 2$ from the tank into electricity minus the amount $X_{i}^{I}$ of $k W h$ used for the production of H2. These decisions concerning the management of the energy storage constitute the operational decision making. That is,

$$
Z_{i}=G_{i}-X_{i}^{I}+X_{i}^{O}
$$

Then, the economic revenue at hour $i$ can be decomposed into two parts: 
- $C_{c_{i}} Y_{i}$, which depends on the committed energy when the tactical decision is made, once per day

- $C_{s_{i}} d_{i}^{+}-\left(C_{c_{i}}+C_{p_{i}}\right) d_{i}^{-}$which depends on both the energy generated at hour $i$ and the operative management decisions of the energy storage system

At every moment when tactical and operational decisions are made, the decision-maker knows the structure of prices and penalties, as well as the amount of energy stored. However, the value $G_{i}$, the amount of energy produced at hour $i$, which is crucial to making both tactical and operational decisions, is not known with certainty. Therefore, the amount of renewable resource available in the future can be considered stochastic. Decisions are made based on a forecast of the renewable resource, which is subject to errors. In an effort to minimize these errors, several forecasts obtained from different types of meteorological methods are considered simultaneously, leading to a probabilistic forecasting ([9] [13], [20] [23]). Specifically, we assume that a probabilistic wind speed forecast (PWSF) at each time $t_{0}$ is available: a set of $m$ predicted wind speed trajectories for the near future. We denote the available probabilistic forecast at time $t_{0}$ by $\boldsymbol{W}\left(t_{0}\right)=\left\{w_{j}(t), \quad t \in\left[t_{o}, t_{u}\right]\right\}_{j=1}^{m}$, where $w_{j}(t)$ is the predicted wind speed for time $t$ in the $j$-th prediction curve. These $m$ different forecasts for the wind speed are used as inputs of the power curve, which converts wind speed to power generation. After this transformation, we obtain a probabilistic forecast of the amount of electricity produced for each of the next $n$ hours: $\boldsymbol{G}_{m}=\left\{\boldsymbol{G}_{i j}, \quad i=1, \ldots, n\right\}_{j=1}^{m}$, where $G_{i j}$ is the $K W h$ generated at hour $i$ associated with the predicted wind speed curve $w_{j}(t)$. Fig. 3 depicts two examples of a PWSF with 25 trajectories. In this figure, the red dotted line represents the actual wind speed and the other trajectories represent the PWSF. In conclusion, the decision-making is performed in a stochastic environment, which has to be taken into account to obtain meaningful results. In the next section, we present a methodological approach for the stochastic optimization that is appropriate for analyzing our problem.

\subsection{Stochastic Average Approximation}

Sample-average approximation (SAA) [27] is a technique used to solve simulation optimization problems. It is applied to problems of the form

\section{$\min _{x \in D} f(x)$}

$x$
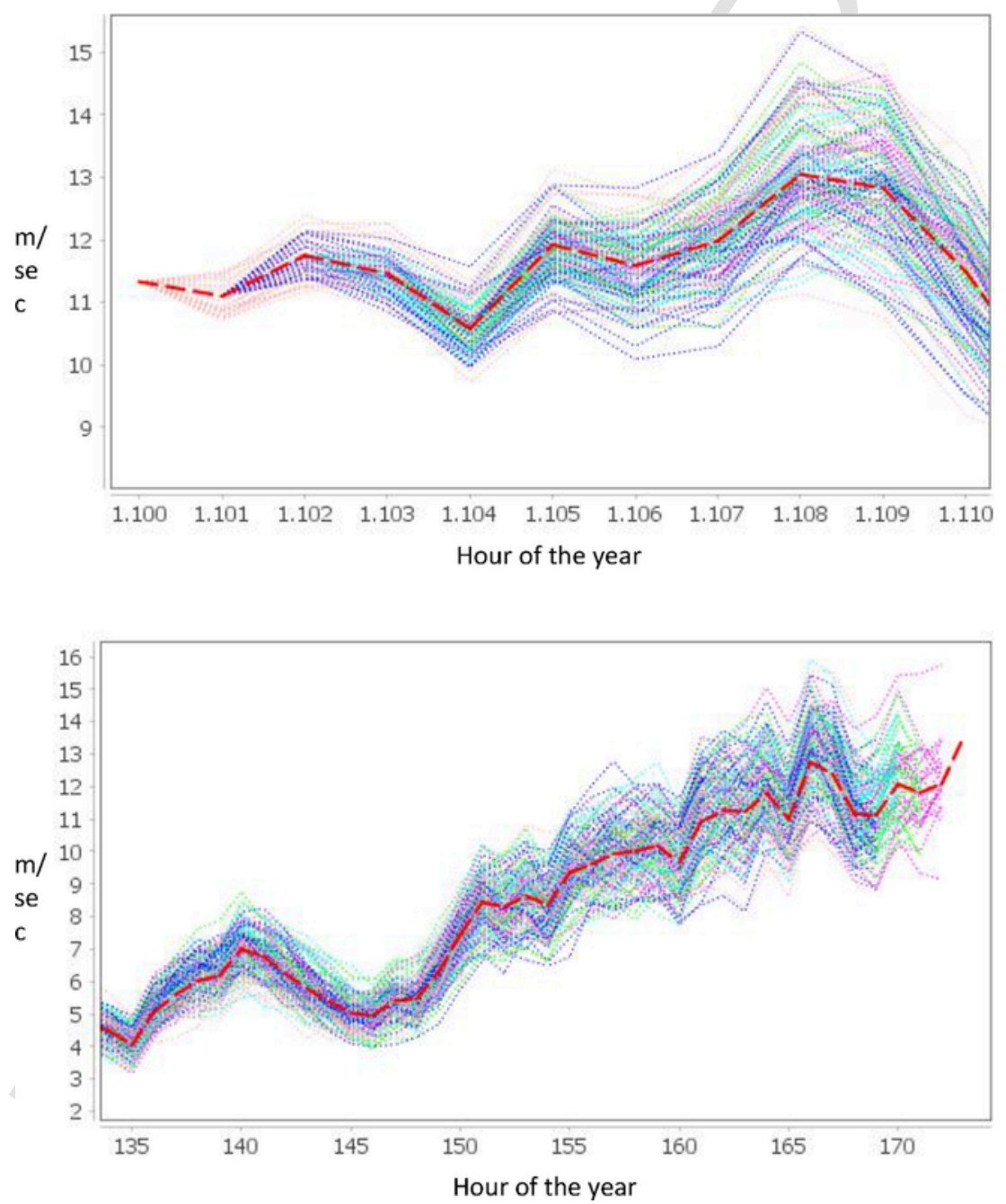

Fig. 3. Examples of a probabilistic wind speed forecast (25 curves). 
where, $D \subseteq \mathbb{R}^{d}$ and the real-valued function $f(x)=E f(x, \xi)$, with $\xi$ a random element whose distribution does not depend on $x$, cannot be observed or computed directly. In SAA, the function $f(x)$ is estimated through simulation by using a sample $\xi_{1}, \xi_{2}, \ldots \xi_{m}$ of $\xi$ . The function $f\left(x, \xi_{i}\right)$ is deterministic and therefore the function $f_{m}(x)=\frac{1}{m} \sum_{i=1}^{m} f\left(x, \xi_{i}\right)$ is. Thus, deterministic optimization techniques can be applied to solve the problem:

$$
\min _{x \in D} f_{m}(x)
$$

The optimal solution $x_{m}^{*}$ of the last problem is taken as the estimator of the optimal solution of the original problem. The solution $x_{m}^{*}$ is expected to converge to the solution of the stochastic problem when it satisfies certain nice structural properties [11]:

1. SAA is appropriate only when the approximating functions $f_{m}$ have some structure that enables the application of an efficient deterministic optimization algorithm, and

2. the limiting function $f$ that we actually want to optimize shares that structure, so that the properties of the limiting function - such as the location of local optima - are similar to those of the approximating function.

The continuity of the objective function presented in the previous section guaranties the achievement of condition 2. The formulation of our problem as a linear programming problem (see the next section) ensures the fulfillment of condition 1 . The reader is referred to [26] for a deep analysis of SAA convergence properties.

\subsection{Formulation of the optimization problem for the energy system operational management}

The operational management of the energy system consists of deciding at each hour how much electricity to release into the grid. This implies management of the energy storage that consists of deciding at each hour $i$ the amount of the generated $\mathrm{kWh}$ that is used to produce hydrogen, denoted by $X_{i}^{I}$, and the amount of kWh that is produced by using the stored hydrogen, denoted by $X_{i}^{O}$. Then, $X_{i}^{I}$ and $X_{i}^{O}$ are the decision variables of the operational optimization problem. The constraints on these values refer to the impossibility of storing a quantity greater than the storage capacity and using more hydrogen than the amount stored in the tank.

Let us suppose that the present time is denoted by $\mathrm{t}=0$ and that the operational problem is to be solved for the next hour, denoted by $t=1$. The mathematical formulation of this problem to determine the optimal values for $X_{1}^{I}$ and $X_{1}^{O}$ is:

[P1] Maximize $C_{c_{1}} Y_{1}+C_{s_{1}} d_{1}^{+}-\left(C_{c_{1}}+C_{p_{1}}\right) d_{1}^{-}$

Subject to $Z_{1}+d_{1}^{-}-d_{1}^{+}=Y_{1}$

$G_{1}-X_{1}^{I}+X_{1}^{O}=Z_{1}$
$T_{1}+e f I X_{1}^{I}-e f O^{-1} X_{1}^{O}=T_{2}$

$X_{1}^{I} \leq$ Cap $_{\text {transf }} /$ efI

$X_{1}^{O} \leq$ Cap $_{\text {Recovery }} *$ efO

$T_{i} \leq \operatorname{Cap}_{\text {Tank }}$

$Z_{1}, d_{1}^{-}, d_{1}^{+}, X_{1}^{I}, X_{1}^{O}, T_{i} \geq 0$

The stochastic objective function was already introduced in equation (1) (section 2.1), and it assesses the profit obtained from the energy sold during the next hour. Constraint (2) measures the deviation between the committed energy $Y_{1}$ and the released energy $Z_{1}$. Constraint (3) expresses the released energy $Z_{1}$ as a function of the generated energy $G_{1}$ and the energy introduced/released to/from the storage, $X_{1}^{I}$ and $X_{1}^{O}$, respectively. The $\mathrm{H} 2$ flow control is considered in constraint (4), where $T_{i}$ represents the amount of $\mathrm{H} 2$ stored at the beginning of period $i$, and $E f I$ and $E f O$ represent the efficiency rates in the transformation process and the recovery process, respectively. Finally, the constraints (5), (6) and (7) represent the transformation, recovery and $\mathrm{H} 2$-tank capacity constraints, respectively.

This optimization problem to maximize the profit at time $t=1$, has a trivial solution: emptying the tank to obtain the maximum profit by the selling of the maximum amount of energy. Clearly, the solution of the problem neglects the consequences in the future evolution of the energy system. To overcome this drawback, two possible alternative formulations of the problem can be considered. The first is to assign an economic value to the energy stored in the tank at the end of the time period (value $T_{2}$ ) and to include it in the objective function:

$$
\text { Maximize } C_{c_{1}} Y_{1}+C_{s_{1}} d_{1}^{+}-\left(C_{c_{1}}+C_{p_{1}}\right) d_{1}^{-}+\alpha T_{2}
$$

However, the solution to this problem is very sensitive to the value of $\boldsymbol{\alpha}$, which is very difficult to calibrate properly.

A more adequate formulation of the optimization problem consists of adopting a rolling horizon strategy, evolving the system into the future. This strategy takes into account both the consequences of current decisions and the future profits from the selling of energy. We propose the following problem considering a horizon of $n$ hours:

[P2] Maximize $\sum_{i=1}^{n} C_{c_{i}} Y_{i}+\sum_{i=1}^{n}\left(C_{s_{i}} d_{i}^{+}-\left(C_{c_{i}}+C_{p_{i}}\right) d_{i}^{-}\right)$

Subject to $Z_{i}+d_{i}^{-}-d_{i}^{+}=Y_{i}$

$G_{i}-X_{i}^{I}+X_{i}^{O}=Z_{i} \quad \mathrm{i}=1, \ldots, \mathrm{n}$ 


$$
T_{i}+e f I X_{i}^{I}-e f O^{-1} X_{i}^{O}=T_{i+1}
$$

$$
X_{i}^{I} \leq \text { Cap }_{\text {transf }} / \text { efI }
$$$$
X_{i}^{O} \leq \text { Cap }_{\text {Recovery }} * e f O
$$

$T_{i} \leq \operatorname{Cap}_{\text {Tank }}$

$$
Z_{i}, d_{i}^{-}, d_{i}^{+}, X_{i}^{I}, X_{i}^{O}, T_{i} \geq 0
$$

Although the formulation of this problem involves the decision variables $X_{i}^{I}, X_{i}^{O}, i=1, \ldots, n$, only the decision variables associated with the first hour, $X_{1}^{I}$ and $X_{1}^{O}$, are necessary to implement the operational control. At the next hour, a new optimization problem with updated information will be formulated to obtain its operational management. That is, variables $X_{i}^{I}, X_{i}^{O}, i=2, \ldots, n$ are only necessary to evolve the system into the future.

At any time, the value of energy committed for the next few hours (at least for the next $12 \mathrm{~h}$ ) is known, and the value of $Y_{i}$ is known. Nevertheless, the problem can include periods of time in which the commitments are not fixed yet. In these cases, $Y_{i}$ is not a parameter but rather a decision variable of the optimization problem.

As we discussed in section 2.1, this problem is stochastic in nature. Let $Q_{i}$ denote the second part of the objective function, which accounts for the consequences of the deviations from the commitments: $Q_{i}=\left(-C_{s_{i}} d_{i}^{+}+\left(C_{c_{i}}+C_{p_{i}}\right) d_{i}^{-}\right)$. At each hour, we seek the best operational management of the energy storage in the sense that it maximizes the total expected revenue during the period of the next $n$ hours.

$$
\begin{aligned}
& \text { Maximize } \sum_{i=1}^{n} C_{c_{i}} Y_{i}-\sum_{i=1}^{n} E\left[Q_{i}\right] \\
& \begin{aligned}
E\left(Q_{i}\right) & =E\left(-C_{s_{i}} d_{i}^{+}+\left(C_{c_{i}}+C_{p_{i}}\right) d_{i}^{-}\right) \\
& =-C_{s_{i}} E\left(d_{i}^{+}\right)+\left(C_{c_{i}}+C_{p_{i}}\right) E\left(d_{i}^{-}\right)
\end{aligned}
\end{aligned}
$$

where we recall that $d_{i}^{+}$and $d_{i}^{-}$are random variables because they are functions of the random variable $G_{i}$, the amount of energy generated at hour $i$ :

$$
G_{i}-X_{i}^{I}+X_{i}^{O}+d_{i}^{-}-d_{i}^{+}=Y_{i}, \quad \text { with } d_{i}^{-}, d_{i}^{+} \geq 0
$$

An $\boldsymbol{S A A}$ inspired algorithm. We propose to solve this stochastic problem using a method inspired by the Stochastic Average Approximation. The application of SAA methodology needs, at every time $t$, a sample of the wind speed random variable. Sensu stricto, this random variable cannot be sampled because it is only observable in the future. However, we can assume that the role of the needed statistical sample is played by the available PWSF.
A direct implementation of the SAA method leads to the following formulation:

$$
\begin{aligned}
& \text { [P3] Maximize } \sum_{i=1}^{n} C_{c_{i}} Y_{i} \\
& +\sum_{i=1}^{n}\left(C_{s_{i}} \frac{1}{m} \sum_{j=1}^{m} d_{i j}^{+}-\left(C_{c_{i}}+C_{p_{i}}\right) \frac{1}{m} \sum_{j=1}^{m} d_{i j}^{-}\right)
\end{aligned}
$$

\section{Subject to}

$$
\begin{aligned}
& G_{i j}-X_{i}^{I}+X_{i}^{O}+d_{i j}^{-}-d_{i j}^{+} \\
& \quad=Y_{i} \quad \mathrm{i} \\
& \quad=1, \ldots, \mathrm{n}, \mathrm{j} \\
& \quad=1 \ldots, \mathrm{m} T_{i}+e f I X_{i}^{I}-e f O^{-1} X_{i}^{O} \\
& \quad=T_{i+1} \mathrm{i} \\
& \quad=1, \ldots, \mathrm{n}
\end{aligned}
$$

$$
Y_{i}, d_{i j}^{+}, d_{i j}^{-}, X_{i j}^{I}, X_{i j}^{O}, T_{i} \geq 0 \quad \forall i, j
$$

Variables $\boldsymbol{d}_{\boldsymbol{i} j}^{-}, \boldsymbol{d}_{\boldsymbol{i} j}^{+}$measure the deviation of the energy released into the grid, $Z_{i j}=G_{i j}-X_{i}^{I}+X_{i}^{O}$, with respect to the committed energy when the $j$-th forecasted energy value for time period $i, G_{i j}$, is considered, and the common operational management, described by variables $X_{i}^{I}, X_{i}^{O}$, is implemented. Then,

$$
\underbrace{G_{i j}-X_{i}^{I}+X_{i}^{O}}_{Z_{i j}}+d_{i j}^{-}-d_{i j}^{+}=Y_{i}
$$

The average of all of these deviations, $\frac{1}{m} \sum_{j=1}^{m} d_{i j}^{+}, \frac{1}{m} \sum_{j=1}^{m} d_{i j}^{-}$, is used as estimation of the expectations $E\left(d_{i}^{+}\right)$and $E\left(d_{i}^{-}\right)$in the objective function.

The main drawback of this formulation is the inflexibility that implies maintaining the same operational decisions in the future, independently of the amount of energy generated in each one of the $m$ wind forecasts. Thus, the operational policy for the tank could dictate retrieval of energy from the tank in the cases of trajectories anticipating a high production of electricity, even though there is sufficient production to satisfy the commitments for that hour; and the opposite may also occur: in cases of low levels of production, the operational decisions could require storing part of the electricity that is necessary 
to fulfill commitments. Therefore, a common policy may be far from optimal in each individual scenario defined by each wind speed trajectory.

To overcome this problem, we propose to modify this straight forward formulation of the SAA algorithm by imposing the same operational management in all forecasted trajectories at the first hour (the one that is implemented in practice) but allowing a specific operational management beyond time $t=1$. The amount of electricity to be released into the grid is obtained as the mean of the values obtained for each of the $m$ wind scenarios. Then, the objective function accounts for the cost resulting from the deviation of this mean value with respect to the value of committed electricity.

[P4] SAA algorithm with future flexible management

$$
\begin{aligned}
& \text { Maximize } \sum_{i=1}^{n} C_{c_{i}} Y_{i}+C_{s_{1}} \frac{1}{m} \sum_{j=1}^{m} d_{1 j}^{+}-\left(C_{c_{1}}+C_{p_{1}}\right) \frac{1}{m} \sum_{j=1}^{m} d_{1 j}^{-} \\
& +\sum_{i=2}^{n}\left(C_{s_{i}} d_{i}^{+}-\left(C_{c_{i}}+C_{p_{i}}\right) d_{i}^{-}\right)
\end{aligned}
$$

Subject to $G_{1 j}-X_{1}^{I}+X_{1}^{O}+d_{1 j}^{-}-d_{1 j}^{+}=Y_{1} \quad \mathrm{j}=1, \ldots, \mathrm{m}$

$T_{1 j}+e f I X_{1}^{I}-e f O^{-1} X_{1}^{O}=T_{2} \quad \mathrm{j}=1, \ldots, \mathrm{m}$

$G_{i j}-X_{i j}^{I}+X_{i j}^{O}=Z_{i j} \quad \mathrm{i}=2, \ldots, \mathrm{n}, \quad \mathrm{j}=1 \ldots, \mathrm{m}$

$T_{i j}+e f I X_{i j}^{I}-e f O^{-1} X_{i j}^{O}=T_{i+1 j} \quad \mathrm{i}=2, \ldots, \mathrm{n}$

$$
Z_{i}=\frac{\sum_{j=1}^{m} Z_{i j}}{m} \quad \mathrm{i}=2, \ldots, \mathrm{n}, \mathrm{j}=1 \ldots, \mathrm{m}
$$

$$
Z_{i}+d_{i}^{-}-d_{i}^{+}=Y_{i} \quad \quad \mathrm{i}=2, \ldots, \mathrm{n}
$$

$$
X_{1}^{I}, X_{i j}^{I} \leq \text { Cap }_{\text {transf }} / \text { efI } \quad \mathrm{i}=2, \ldots, \mathrm{n}, \mathrm{j}=1 \ldots, \mathrm{m}
$$

$X_{1}^{O}, \quad X_{i j}^{O} \leq$ Cap $_{\text {Recovery }} *$ efO $\mathrm{i}=2, \ldots, \mathrm{n}, \mathrm{j}=1 \ldots, \mathrm{m}$

$T_{i j} \leq \operatorname{Cap}_{\text {Tank }} \mathrm{i}=2, \ldots, \mathrm{n}, \mathrm{j}=1 \ldots, \mathrm{m}$

$$
Z_{i}, Z_{i j}, d_{i}^{-}, d_{i}^{+}, X_{1}^{O}, X_{1}^{I}, X_{i j}^{I}, X_{i j}^{O}, T_{i j} \geq 0
$$

Observe that constraints (8) and (9) were already included in the formulation of [P1], while (10) defines the amount of $\mathrm{kWh}$ to be released in the future according to each wind trajectory, (11) assures that the employed policies are feasible, (12) estimates the expected $\mathrm{kWh}$ released into the grid and (13) evaluates the deviations of this average with respect to the committed $\mathrm{kWh}$. The remaining con- straints, (14), (15) and (16), are the capacity constraints that were already used in previous problems.

\subsection{Formulation of the optimization problem for the energy system tactical management}

Once per day, the managers should decide how much energy to commit for each of the $24 \mathrm{~h}$ of the day ahead. This problem is solved by formulating a problem similar to the previous one [P4]. The difference is that the $Y_{i}$ are known parameters for the indices $i$ corresponding to decision hours of the current day, but they are decision variables for each of the $24 \mathrm{~h}$ of the next two days, and the values obtained for the variables $Y_{i}$ in the next day define the tactical decisions because they are considered as the electricity selling commitments. Suppose that the decision is made every day at 12 a.m., then $t=1$ corresponds to the hour from 12 a.m. to 1 p.m., $t=2$ to the hour from 1 p.m. to 2 p.m., and so on. The commitments for the $12 \mathrm{~h}$ ranging from 12 a.m. to 12 p.m. are known because they were fixed the day before. Then, the decision variables are $Y_{i}$ for $\mathrm{i}=13, \ldots ., 36$, which will provide the energy that should be committed for each of the $24 \mathrm{~h}$ of the day ahead. Sometimes the time horizon extends further because it is common to obtain a wind speed forecast for the rest of the day plus two whole days. In terms of hours, this would mean that there are decision variables $Y_{i}$ for $\mathrm{i}=37, \ldots, 60$, which are used to evolve the operation of the energy system into the future.

\section{Illustrative examples and results}

To illustrate the methodology to obtain both tactical and operational management policies, we consider a renewable wind-farm system with H2-based storage inspired by a real system that was the subject of previous research [1]. An experimental wind-farm was built in Sotavento, Spain, to explore energy storage systems and their management [31].

We developed a discrete time simulation model to test the management policies in different environments defined by the electricity prices, by the accuracy of the PWSF and by different wind regimes. The simulation model incorporated all of the important equipment that comprises the wind-H2 energy system [1]. The wind-farm was characterized by its power capacity and its wind-power conversion curve. The H2-tank was described by its capacity. The electrolyzers, compressor, and the various technologies involved in the recovery process were specified by both their capacities and their efficiency curves.

Key features in our management strategy are the updated PWSF and the integration of the tactical and the operational decisions within a single mathematical model. Our model simulates the PWSF at each hour through the simulation of $m$ wind trajectories. This model handles the prediction errors as follows. The wind speed predictions are simulated by adding an error to the historical wind speed series. The error is obtained by combining the absolute and relative errors. The relative error depends on the prediction horizon and increases as the horizon extends. To smooth the predicted energy curve, an auto-correlated error series is generated from a record of past errors. For more details about this wind-speed simulation model, see Ref. [17] (a similar model is used in Ref. [19]). Furthermore, a temporal displacement of the forecasted trajectories is incorporated to simulate phase errors, which are of great importance because they may easily produce a significant energy imbalance. Thus, the accuracy of the probabilistic forecast can be controlled through the error, magnitude and temporal components [8]. 
Actual wind speed data are used to drive the simulation, whereas the PWSF is used as an input to the optimization problems to obtain the tactical and operational management policies. Specifically, for each hour, the updated PSWF is simulated along with the associated energy production. Taking into account the probabilistic renewable energy forecast, the quantity of hydrogen stored in the tank, and the amount of pre-committed electricity for the next hour, the optimization problem [P4] is formulated and solved to obtain the operational policy for the next hour. When the simulation clock reaches the time at which the energy supply commitments for the following day need to be announced (at 12 a.m.), these values are determined by solving the optimization problem [P4] wherein the decision variables $Y_{i}$ for $i=13, \ldots ., 36$ are used as commitments of energy for the $24 \mathrm{~h}$ of the day ahead.

We conducted different simulation experiments by using historical hourly wind speed data. We present simulation results considering both one-year data and three specific patterns of wind speed: periods of low wind speed, (Fig. 4-a), long periods of high wind speed (Fig. 4-b), and periods with oscillating wind speed (Fig. 4-c).

A maximum absolute error of $2 \mathrm{~m} / \mathrm{sec}$ and two ranges of relative error, $[0 \%, 50 \%]$ and $[0 \%, 100 \%]$, are set. This means that at the end of the forecasting horizon, the magnitude of the relative error can be any percentage of the real wind between 0 and $50 \%$ or $100 \%$. We consider an H2-tank with an 800 equivalent-kWh storage capacity, efficiencies of $60 \%$ and $80 \%$ for the electricity- $\mathrm{H} 2$ transformation system and the recovery system, respectively (thus, an efficiency of $48 \%$ for the whole storage system). We use real hourly energy prices for committed energy, $C_{C_{i}}$, and we explore different penalty and surplus $\operatorname{prices}\left(C_{P_{i}}=0.3, C_{S_{i}}=0.5\right.$ and $\left.C_{P_{i}}=0.7, C_{S_{i}}=0.1\right) . \quad$ The optimization problems are solved with a rolling horizon of $61 \mathrm{~h}$.

The management policy $O+T$ proposed in this paper is implemented using one, ten and thirty curves in the PWSF $(O+T$-Manag. columns in the tables). These results are compared with the policy that only optimizes the tactical decisions and operates the tank in an attempt to meet the commitments for each hour by using the tank if necessary and storing any surplus (Tact-Manag. column, strategy proposed in Ref. [1].) The results comprise a standardized economic assessment of the system (Profit row); the standardized amount of energy committed (Commitments row); an assessment of the system reliability by providing the percentage of committed energy not supplied ( $\%$ Commits not supplied row); the percentage of energy sold above commitments (\% Surplus row); and the assessment of the use of the tank measured through the percentage of energy sold obtained from the tank storage ( $\% \mathrm{kWh}$ from the tank row).

Tables 2-4 show simulation results considering the three different wind patterns represented in Fig. 4-a, 4-b, and 4-c, respectively. The results for a 1-year wind period are presented in Tables 5 and 6 , and in the latter, the PWSF includes a 1-h displacement in the temporal axis to simulate phase errors. Finally, Tables 7 and 8 present experimental results for the case in which the storage of energy is not available, using PWSF without and with phase errors in the predictions, respectively.

The results show that a greater benefit is obtained when the tactical and operational decisions are integrated than when the decisions are made separately. In the case of a single wind curve, the profit improvement can reach $5 \%$ in the simulation of a full year (profit values 0.949 and 0.943 in column Tact-Manag in Table 5).

The availability of PWSF improves the economic benefit. The profit increase can exceed $10 \%$ in cases of final relative forecasting errors of $50 \%$ and can be near $10 \%$ when the forecasting errors increase to $100 \%$ (see results in Tables 2 and 4). However, this im- provement due to PWSF in the case of high wind periods (Table 3 ) is less.

Regarding the system reliability, the Tact-Manag is slightly better than $O+T$-Manag when only one prediction curve is used; however, the system reliability is significantly enhanced when a probabilistic forecast is available. See, for example, the results in Tables 2 and 4 , which show reliability values of approximately $11-12 \%$ for the $O+T$-Manag 1-curve-case, $10-11 \%$ for the Tact-Manag case, and an improvement for the PWSF case, in which the percentage of commitments not supplied decreased to $3.3-4.7 \%$.

The use of the tank in situations with strong winds (Table 3 ) is lower compared to other more irregular wind patterns (Tables 2 and 4). These tables also reveal that the PWSF achieves reduced tank usage.

Tables 6 and 8 demonstrate that phase errors in the wind forecast hinder the management of the system. For example, considering penalties of $30 \%$, we observe a decrease of $4 \%-6 \%$ in the profits for 1-year experiments (Table 6) in comparison with the same experiments without phase errors (Table 5). This profit decrease is accentuated in the case of $70 \%$ penalties, approaching $10 \%$ for the PWSF cases. This worsening is also observed in the reliability when comparing the percentage of commitments not supplied, with values of approximately $12 \%$ for the single forecast case and final relative error of $100 \%$. For the PWSF case, the results in Table 6 show values over $6 \%$ for $50 \%$ final relative errors, while the same scenario without temporal errors (Table 5) has approximately a $1 \%$ failure in commitments.

Finally, when only the tactical decisions are considered and no storage is available, the results in Table 7 show a soft decrease in the profit and a worsening in the system reliability. Furthermore, this behavior is emphasized when the temporal errors in forecasting are considered (Table 8), reaching $16.31 \%$ of commitments not supplied.

\section{Conclusions}

In this paper, we proposed a management strategy for a renewable energy system with a storage capacity that includes tactical and operational decisions in a single mathematical model, which makes use of an updated PWSF. In this way, decisions regarding the sale of energy commitments in the electricity market and the operation of the energy storage are integrated in the same decision framework. The mathematical optimization problem is stochastic and has been solved by using an approach based on the Stochastic Approximation Average technique.

We tested the new management strategies by developing a simulation model, and the results indicate that a greater benefit is obtained when the tactical and operational decisions are integrated than when the decisions are made separately. The superiority of the new management strategy is reinforced by the use of PWSF, which increases the reliability of the renewable energy as a provider of committed energy. Finally, the advantage of having energy storage has been demonstrated in all of the studied scenarios.

The management policies presented in this paper were illustrated for wind-farms and H2-based energy storage. However, these policies can be adapted easily to other renewable sources and other methods of storing energy.

Finally, the optimization was carried out by using an economic objective function, and although the results related to the reliability of the energy system as a provider of energy were presented, this reliability goal was explicitly included in the optimization problems. The consideration of this objective would lead to bi-objective optimiza- 

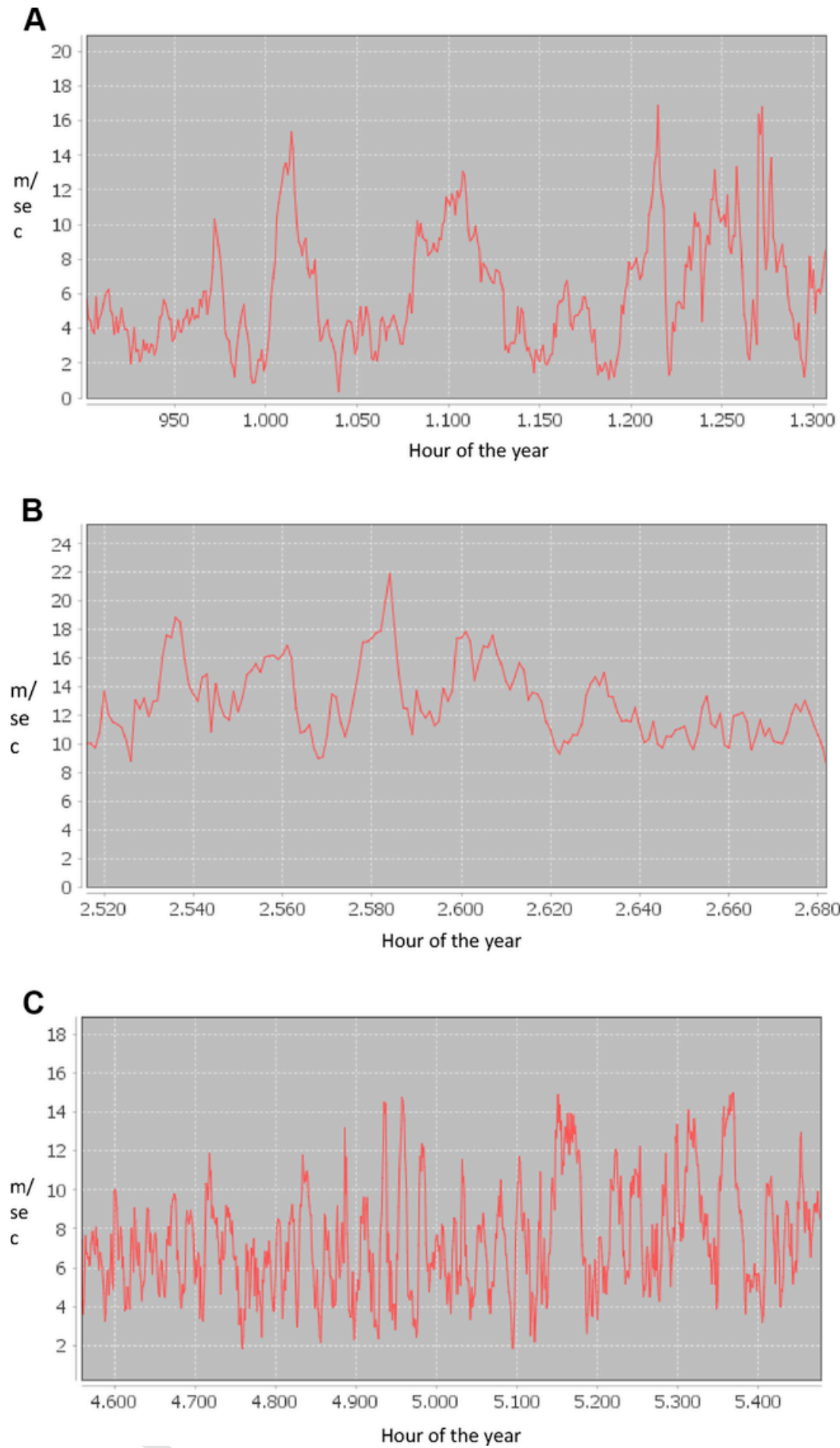

Fig. 4. Different wind speed patterns: periods of low wind speed, (Fig. 4-a), long periods of high wind speed (Fig. 4-b), and periods of oscillating wind speed (Fig. 4-c).

tion problems to represent the trade-off between reliability and profit achievements.

\section{Acknowledgments}

The authors are grateful to the research staff of the National Renewable Energy Centre in Spain (CENER) for technical support and advice in understanding energy storage systems. This paper has been supported in part by grant MTM2012-36025. 
Table 2

Experimental results for wind oscillation including periods around zero-wind in Fig. 3-a.

\begin{tabular}{|c|c|c|c|c|c|c|c|c|c|}
\hline & & \multicolumn{4}{|c|}{ Final relative forecasting error $=100 \%$} & \multicolumn{4}{|c|}{ Final relative forecasting error $=50 \%$} \\
\hline & & \multicolumn{3}{|c|}{ PWSF $O+T$-Manag. } & \multirow{2}{*}{$\frac{\text { Tact-Manag }}{1}$} & \multicolumn{3}{|c|}{ PWSF $O+T$-Manag. } & \multirow{2}{*}{$\frac{\text { Tact-Manag }}{1}$} \\
\hline & & 1 & 10 & 30 & & 1 & 10 & 30 & \\
\hline \multirow{5}{*}{$\begin{array}{c}\mathrm{Cp}=0.3 \\
\mathrm{Cs}=0.5\end{array}$} & Profit & 1 & 1.087 & 1.096 & 0.987 & 1.060 & 1.107 & 1.115 & 1.051 \\
\hline & Commitments & 1 & 1.013 & 1.000 & 0.999 & 1.005 & 1.012 & 1.002 & 1.006 \\
\hline & $\%$ Commits not supplied & 11.41 & 4.76 & 3.28 & 9.87 & 6.15 & 2.66 & 1.35 & 5.33 \\
\hline & $\%$ Surplus & 9.44 & 3.32 & 3.1 & 7.44 & 4.46 & 1.41 & 1.08 & 3.29 \\
\hline & $\% \mathrm{kWs}$ from the tank & 5.85 & 4.37 & 4.22 & 6.37 & 5.04 & 4.16 & 4.04 & 5.31 \\
\hline \multirow{4}{*}{$\begin{array}{c}\mathrm{Cp}=0.7 \\
\mathrm{Cs}=0.1\end{array}$} & Profit & 1 & 1.167 & 1.185 & 0.997 & 1.117 & 1.207 & 1.223 & 1.112 \\
\hline & Commitments & 1 & 1.007 & 0.995 & 0.999 & 1.006 & 1.009 & 1.000 & 1.006 \\
\hline & $\%$ Commits not supplied & 11.15 & 4.13 & 2.92 & 9.89 & 6.18 & 2.36 & 1.27 & 5.45 \\
\hline & $\%$ Surplus & 8.53 & 3.0 & 2.93 & 7.37 & 4.06 & 1.27 & 1.12 & 3.29 \\
\hline
\end{tabular}

Table 3

Experimental results for high wind periods in Fig. 3-b.

\begin{tabular}{|c|c|c|c|c|c|c|c|c|c|}
\hline & & \multicolumn{4}{|c|}{ Final relative forecasting error $=100 \%$} & \multicolumn{4}{|c|}{ Final relative forecasting error $=50 \%$} \\
\hline & & \multicolumn{3}{|c|}{$P W S F O+T$-Manag. } & \multirow{2}{*}{$\frac{\text { Tact-Manag }}{1}$} & \multicolumn{3}{|c|}{ PWSF $O+T$-Manag. } & \multirow{2}{*}{$\frac{\text { Tact-Manag }}{1}$} \\
\hline & & 1 & 10 & 30 & & 1 & 10 & 30 & \\
\hline \multirow{5}{*}{$\begin{array}{c}\mathrm{Cp}=0.3 \\
\mathrm{Cs}=0.5\end{array}$} & Profit & 1 & 1.030 & 1.031 & 0.996 & 1.037 & 1.050 & 1.052 & 1.034 \\
\hline & Commitments & 1 & 1.014 & 1.008 & 1.000 & 1.053 & 1.052 & 1.051 & 1.053 \\
\hline & $\%$ Commits not supplied & 2.83 & 0.28 & 0.06 & 2.49 & 1.62 & 0.26 & 0.07 & 1.33 \\
\hline & $\%$ Surplus & 7.1 & 3.91 & 4.31 & 6.43 & 1.36 & 0.42 & 0.35 & 0.67 \\
\hline & $\% \mathrm{kWs}$ from the tank & 1.62 & 1.09 & 0.99 & 1.96 & 1.36 & 0.99 & 0.97 & 1.66 \\
\hline \multirow{5}{*}{$\begin{array}{c}\mathrm{Cp}=0.7 \\
\mathrm{Cs}=0.1\end{array}$} & Profit & 1 & 1.054 & 1.053 & 0.999 & 1.067 & 1.090 & 1.092 & 1.066 \\
\hline & Commitments & 1 & 1.014 & 1.008 & 1.000 & 1.052 & 1.053 & 1.051 & 1.053 \\
\hline & $\%$ Commits not supplied & 2.6 & 0.11 & 0.02 & 2.49 & 1.5 & 0.16 & 0.04 & 1.33 \\
\hline & $\%$ Surplus & 6.67 & 3.57 & 4.24 & 6.44 & 1.19 & 0.34 & 0.28 & 0.67 \\
\hline & $\% \mathrm{kWs}$ from the tank & 1.85 & 1.24 & 1.02 & 1.96 & 1.49 & 1.08 & 1.01 & 1.66 \\
\hline
\end{tabular}

Table 4

Experimental results for regular wind periods in Fig. 3-c.

\begin{tabular}{|c|c|c|c|c|c|c|c|c|c|}
\hline & & \multicolumn{4}{|c|}{ Final relative forecasting error $=100 \%$} & \multicolumn{4}{|c|}{ Final relative forecasting error $=50 \%$} \\
\hline & & \multicolumn{3}{|c|}{ PWSF $O+T$-Manag. } & \multirow{2}{*}{$\frac{\text { Tact-Manag }}{1}$} & \multicolumn{3}{|c|}{ PWSF $O+T$-Manag. } & \multirow{2}{*}{$\frac{\text { Tact-Manag }}{1}$} \\
\hline & & 1 & 10 & 30 & & 1 & 10 & 30 & \\
\hline \multirow{5}{*}{$\begin{array}{c}\mathrm{Cp}=0.3 \\
\mathrm{Cs}=0.5\end{array}$} & Profit & 1 & 1.082 & 1.095 & 0.986 & 1.063 & 1.108 & 1.129 & 1.053 \\
\hline & Commitments & 1 & 1.024 & 1.030 & 0.999 & 1.010 & 1.025 & 1.020 & 1.008 \\
\hline & $\%$ Commits not supplied & 12.16 & 4.38 & 3.61 & 11.45 & 5.96 & 2.1 & 0 & 5.28 \\
\hline & $\%$ Surplus & 11.72 & 2.66 & 1.73 & 10.3 & 5.02 & 0.81 & 0 & 3.83 \\
\hline & $\% \mathrm{kWs}$ from the tank & 4.43 & 3.19 & 2.78 & 5.02 & 3.89 & 2.74 & 2.18 & 4.38 \\
\hline \multirow{5}{*}{$\begin{array}{c}\mathrm{Cp}=0.7 \\
\mathrm{Cs}=0.1\end{array}$} & Profit & 1 & 1.174 & 1.196 & 0.995 & 1.132 & 1.222 & 1.234 & 1.129 \\
\hline & Commitments & 1 & 1.021 & 1.028 & 1.000 & 1.009 & 1.024 & 1.026 & 1.008 \\
\hline & $\%$ Commits not supplied & 11.85 & 3.93 & 3.28 & 11.34 & 5.69 & 1.82 & 1.38 & 5.22 \\
\hline & $\%$ Surplus & 11.22 & 2.33 & 1.44 & 10.25 & 4.73 & 0.55 & 0.41 & 3.86 \\
\hline & $\% \mathrm{kWs}$ from the tank & 4.82 & 3.56 & 3.07 & 5.09 & 4.21 & 2.96 & 2.58 & 4.44 \\
\hline
\end{tabular}


Table 5

Experimental results for 1 year of wind data.

\begin{tabular}{|c|c|c|c|c|c|c|c|c|c|}
\hline & & \multicolumn{4}{|c|}{ Final relative forecasting error $=100 \%$} & \multicolumn{4}{|c|}{ Final relative forecasting error $=50 \%$} \\
\hline & & \multicolumn{3}{|c|}{ PWSF $O+T$-Manag. } & \multirow{2}{*}{$\frac{\text { Tact-Manag }}{1}$} & \multicolumn{3}{|c|}{ PWSF $O+T$-Manag. } & \multirow{2}{*}{$\frac{\text { Tact-Manag }}{1}$} \\
\hline & & 1 & 10 & 30 & & 1 & 10 & 30 & \\
\hline \multirow{5}{*}{$\begin{array}{c}\mathrm{Cp}=0.3 \\
\mathrm{Cs}=0.5\end{array}$} & Profit & 1 & 1.050 & 1.059 & 0.949 & 1.047 & 1.075 & 1.080 & 1.024 \\
\hline & Commitments & 1 & 0.978 & 0.979 & 0.913 & 1.004 & 0.991 & 0.991 & 0.973 \\
\hline & $\%$ Commits not supplied & 9.86 & 3.42 & 2.61 & 7.47 & 5.17 & 1.63 & 1.12 & 4.04 \\
\hline & $\%$ Surplus & 7.29 & 3.91 & 3.33 & 12.0 & 2.75 & 1.15 & 0.86 & 3.88 \\
\hline & $\% \mathrm{kWs}$ from the tank & 4.03 & 3.03 & 2.73 & 5.3 & 3.34 & 2.73 & 2.53 & 4.13 \\
\hline \multirow{5}{*}{$\begin{array}{c}\mathrm{Cp}=0.7 \\
\mathrm{Cs}=0.1\end{array}$} & Profit & 1 & 1.102 & 1.117 & 0.943 & 1.093 & 1.148 & 1.157 & 1.051 \\
\hline & Commitments & 1 & 0.978 & 0.980 & 0.914 & 1.004 & 0.991 & 0.992 & 0.940 \\
\hline & $\%$ Commits not supplied & 9.45 & 3.16 & 2.37 & 7.11 & 4.89 & 1.44 & 0.98 & 3.52 \\
\hline & $\%$ Surplus & 6.75 & 3.64 & 3.04 & 11.41 & 2.46 & 1.01 & 0.74 & 6.35 \\
\hline & $\% \mathrm{kWs}$ from the tank & 4.36 & 3.21 & 2.89 & 5.61 & 3.55 & 2.85 & 2.62 & 4.58 \\
\hline
\end{tabular}

Table 6

Experimental results for 1 year of wind data, with a 1-h temporal displacement in the forecasted trajectories.

\begin{tabular}{|c|c|c|c|c|c|c|c|c|c|}
\hline & & \multicolumn{8}{|c|}{ Phase error (1-h temporal displacement) } \\
\hline & & \multicolumn{8}{|c|}{ Final relative forecasting error $=100 \%$} \\
\hline & & \multicolumn{3}{|c|}{$P W S F O+T$-Manag. } & Tact-Manag & \multicolumn{3}{|c|}{$P W S F O+T-M a n a g}$. & \multirow{2}{*}{$\frac{\text { Tact-Manag }}{1}$} \\
\hline & & 1 & 10 & 30 & 1 & $1 \longdiv { y }$ & 10 & 30 & \\
\hline \multirow{5}{*}{$\begin{array}{c}\mathrm{Cp}=0.3 \\
\mathrm{Cs}=0.5\end{array}$} & Profit & 0.961 & 1.005 & 1.009 & 0.937 & 1.001 & 1.018 & 1.019 & 0.987 \\
\hline & Commitments & 0.976 & 0.977 & 0.983 & 0.944 & 0.993 & 0.994 & 0.997 & 0.990 \\
\hline & $\%$ Commits not supplied & 12.45 & 7.43 & 7.36 & 10.47 & 8.78 & 6.89 & 6.98 & 7.27 \\
\hline & $\%$ Surplus & 10.74 & 5.7 & 5.09 & 10.35 & 5.41 & 3.3 & 3.08 & 2.86 \\
\hline & $\% \mathrm{kWs}$ from the tank & 5.49 & 5.35 & 5.3 & 7.0 & 5.47 & 5.55 & 5.53 & 6.82 \\
\hline \multirow{5}{*}{$\begin{array}{c}\mathrm{Cp}=0.7 \\
\mathrm{Cs}=0.1\end{array}$} & Profit & 0.938 & 1.033 & 1.041 & 0.868 & 1.023 & 1.060 & 1.062 & 1.016 \\
\hline & Commitments & 0.976 & 0.974 & 0.980 & 0.875 & 0.992 & 0.992 & 0.994 & 0.991 \\
\hline & $\%$ Commits not supplied & 11.75 & 6.64 & 6.49 & 9.70 & 8.02 & 6.11 & 6.12 & 7.25 \\
\hline & $\%$ Surplus & 9.6 & 4.74 & 4.0 & 16.15 & 4.18 & 2.27 & 2.06 & 2.94 \\
\hline & $\% \mathrm{kWs}$ from the tank & 6.17 & 6.0 & 6.0 & 7.25 & 6.22 & 6.22 & 6.23 & 6.84 \\
\hline
\end{tabular}

Table 7

Experimental results for 1 year of wind data, without tank storage.

\begin{tabular}{|c|c|c|c|c|c|c|c|}
\hline & & \multicolumn{3}{|c|}{$\begin{array}{l}\text { Final relative forecasting } \\
\text { error }=100 \%\end{array}$} & \multicolumn{3}{|c|}{$\begin{array}{l}\text { Final relative forecasting } \\
\text { error }=50 \%\end{array}$} \\
\hline & & \multicolumn{2}{|c|}{$\begin{array}{l}P W S F O+T- \\
\text { Manag. }\end{array}$} & \multirow{2}{*}{$\begin{array}{l}\text { Tact- } \\
\text { Manag }\end{array}$} & \multicolumn{2}{|c|}{$\begin{array}{l}P W S F O+T- \\
\text { Manag. }\end{array}$} & \multirow{2}{*}{$\begin{array}{l}\text { Tact- } \\
\text { Manag }\end{array}$} \\
\hline & & 10 & 30 & & 10 & 30 & \\
\hline \multirow{4}{*}{$\begin{array}{l}\mathrm{Cp}=0.3 \\
\mathrm{Cs}=0.5\end{array}$} & Profit & 1.037 & 1.047 & 0.980 & 1.065 & 1.071 & 1.032 \\
\hline & Commitments & 0.994 & 0.995 & 1.010 & 1.011 & 1.010 & 1.018 \\
\hline & $\begin{array}{l}\% \text { Commits not } \\
\text { supplied }\end{array}$ & 4.30 & 3.22 & 11.72 & 2.08 & 1.40 & 6.20 \\
\hline & $\%$ Surplus & 6.31 & 5.17 & 12.17 & 2.51 & 1.85 & 5.95 \\
\hline \multirow{4}{*}{$\begin{array}{l}\mathrm{Cp}=0.7 \\
\mathrm{Cs}=0.1\end{array}$} & Profit & 1.070 & 1.091 & 0.943 & 1.128 & 1.141 & 1.056 \\
\hline & Commitments & 0.996 & 0.997 & 1.012 & 1.013 & 1.013 & 1.020 \\
\hline & $\begin{array}{l}\% \text { Commits not } \\
\text { supplied }\end{array}$ & 4.30 & 3.22 & 11.72 & 2.08 & 1.40 & 6.20 \\
\hline & $\%$ Surplus & 6.31 & 5.17 & 12.17 & 2.51 & 1.85 & 5.95 \\
\hline
\end{tabular}

Table 8

Experimental results for 1 year of wind data, without tank storage, with a 1-h temporal displacement in the forecasted trajectories.

\begin{tabular}{|c|c|c|c|c|c|c|c|}
\hline & & \multicolumn{6}{|c|}{ Phase error (1-h temporal displacement) } \\
\hline & & \multicolumn{3}{|c|}{$\begin{array}{l}\text { Final relative forecasting } \\
\text { error }=100 \%\end{array}$} & \multicolumn{3}{|c|}{$\begin{array}{l}\text { Final relative forecasting } \\
\text { error }=50 \%\end{array}$} \\
\hline & & \multicolumn{2}{|c|}{$\begin{array}{l}P W S F O+T- \\
\text { Manag. }\end{array}$} & \multirow{2}{*}{$\begin{array}{l}\text { Tact- } \\
\text { Manag }\end{array}$} & \multicolumn{2}{|c|}{$\begin{array}{l}P W S F O+T- \\
\text { Manag. }\end{array}$} & \multirow{2}{*}{$\begin{array}{l}\text { Tact- } \\
\text { Manag }\end{array}$} \\
\hline & & 10 & 30 & & 10 & 30 & \\
\hline \multirow{4}{*}{$\begin{array}{l}\mathrm{Cp}=0.3 \\
\mathrm{Cs}=0.5\end{array}$} & Profit & 0.977 & 0.980 & 0.931 & 0.989 & 0.990 & 0.972 \\
\hline & Commitments & 0.988 & 0.994 & 0.986 & 1.007 & 1.010 & 1.005 \\
\hline & $\begin{array}{l}\% \text { Commits not } \\
\text { supplied }\end{array}$ & 11.06 & 10.88 & 16.31 & 10.57 & 10.59 & 12.46 \\
\hline & \% Surplus & 13.4 & 12.73 & 18.65 & 11.27 & 11.01 & 13.28 \\
\hline \multirow{4}{*}{$\begin{array}{l}\mathrm{Cp}=0.7 \\
\mathrm{Cs}=0.1\end{array}$} & Profit & 0.940 & 0.947 & 0.841 & 0.964 & 0.966 & 0.927 \\
\hline & Commitments & 0.990 & 0.996 & 0.989 & 1.009 & 1.012 & 1.007 \\
\hline & $\begin{array}{l}\% \text { Commits not } \\
\text { supplied }\end{array}$ & 11.06 & 10.88 & 16.31 & 10.57 & 10.59 & 12.46 \\
\hline & $\%$ Surplus & 13.4 & 12.73 & 18.65 & 11.27 & 11.01 & 13.28 \\
\hline
\end{tabular}

\section{References}

[1] M. Aguado, E. Ayerbe, C. Azcárate, R. Blanco, Garde, F. Mallor, D. Rivas, Economical assessment of a wind-hydrogen energy system using WindHyGen ${ }^{\circledR}$ 
software, Int. J. Hydrogen Energy 34 (2009) 2845-2854, http://dx.doi.org/10. 1016/j.ijhydene.2008.12.098.

[2] C. Azcárate, R. Blanco, F. Mallor, R. Garde, M. Aguado, Peaking strategies for the management of wind-H2 energy systems, Renew. Energy 47 (2012) 103-111, http://dx.doi.org/10.1016/j.renene.2012.04.016.

[3] M. Beaudin, H. Zareipour, A. Schellenberglabe, W. Rosehart, Energy storage for mitigating the variability of renewable electricity sources: an updated review, Energy Sust. Dev. 14 (2010) 302-314, http://dx.doi.org/10.1016/j.esd. 2010.09.007.

[4] D. Connolly, H. Lund, B.V. Mathiesen, E. Pican, M. Leahy, The technical and economic implications of integrating fluctuating renewable energy using energy storage, Renew. Energy 43 (2012) 47-60, http://dx.doi.org/10.1016/j.renene. 2011.11.003.

[5] H. Chen, T.N. Cong, W. Yang, C. Tan, Y. Li, Y. Ding, Progress in electrical energy storage system: a critical review, Prog. Nat. Sci. 19 (2009) 291-312, http:// dx.doi.org/10.1016/j.pnsc.2008.07.014.

[6] F. Diaz-González, A. Sumper, O. Gomis-Bellmunt, R. Villafáfila-Robles, A review of energy storage technologies for wind power applications, Renew. Sustain. Energy Rev. 16 (4) (2012) 2154-2171, http://dx.doi.org/10.1016/j.rser. 2012.01.029.

[7] A. Evans, V. Strezov, T.J. Evans, Assessment of utility energy storage options for increased renewable energy penetration, Renew. Sustain. Energy Rev. 16 (2012) 141-147, http://dx.doi.org/10.1016/j.rser.2012.03.048.

[8] L. Frías-Paredes, F. Mallor, T. León, M. Gastón-Romeo, Introducing the Temporal Distortion Index to perform a bidimensional analysis of renewable energy forecast, Energy 94 (2016) 180-194, http://dx.doi.org/10.1016/j.energy.2015.10. 093.

[9] T. Gneiting, A.E. Raftery, Weather forecasting with ensemble methods, Science 310 (2005) 248-249, http://dx.doi.org/10.1126/science.1115255.

[10] K. Hedegaard, P. Meibom, Wind power impacts and electricity storage-A time scale perspective, Renew. Energy 37 (1) (2012) 318-324, http://dx.doi.org/10. 1016/j.renene.2011.06.034.

[11] S. Kim, R. Pasupathy, S.G. Henderson, A guide to sample average approximation, In: M.C. Fu (Ed.), Handbook of Simulation Optimization, International Series in Operations Research \& Management Science, vol. 216, Springer, New York, 2015http://dx.doi.org/10.1007/978-1-4939-1384-8 8 .

[12] P. Kou, F. Gao, X. Guan, Stochastic predictive control of battery energy storage for wind farm dispatching: using probabilistic wind power forecasts, Renew. Energy 80 (2015) 286-300, http://dx.doi.org/10.1016/j.renene.2015.02.001.

[13] M. Leutbecher, T.N. Palmer, Ensemble forecasting, J. Comput. Phys. 227 (12) (2008) 3515-3539, http://dx.doi.org/10.1016/j.jcp.2007.02.014.

[14] C. Liu, F. Li, L.P. Ma, H.M. Cheng, Advanced materials for energy storage, Adv. Mater. 22 (2010) E28-E62, http://dx.doi.org/10.1002/adma.200903328.

[15] H. Lund, G. Salgi, The role of compressed air energy storage (CAES) in future sustainable energy systems, Energy Convers. Manag. 50 (5) (2009) 1172-1799, http://dx.doi.org/10.1016/j.enconman.2009.01.032.
[16] X. Luo, J. Wang, M. Dooner, J. Clarke, Overview of current development in electrical energy storage technologies and the application potential in power system operation, Appl. Energy 137 (2015) 511-536, http://dx.doi.org/10.1016/ j.apenergy.2014.09.081.

[17] F. Mallor, C. Azcárate, R. Blanco, Including risk in management models for the simulation of energy production systems, In: Proceedings of the 39th International Conference on Computers \& Industrial Engineering., Computers Industrial Eng, IEEE CNF, 2009, pp. 1821-1826.

[18] F. Mallor, C. Azcárate, R. Blanco, P. Mateo, Operational management of renewable energy systems with storage using an optimisation-based simulation methodology, J. Simul. 9 (4) (2015) 263-278, http://dx.doi.org/10.1057/jos. 2015.16.

[19] P. Meibom, R. Barth, B. Hasche, H. Brand, C. Weber, M. O'Malley, Stochastic optimization model to study the operational impacts of high wind penetrations in Ireland, IEEE Trans. Power Syst. 26 (3) (2011) 1367-1379, http://dx.doi.org/ 10.1109/TPWRS.2010.2070848.

[20] C. Moehrlen, Uncertainty in Wind Energy Forecasting, PhD thesis University College Cork, 2004

[21] C. Monteiro, R. Bessa, V. Miranda, A. Botterud, J. Wang, G. Conzelmann, Wind Power Forecasting: State-of-the-art, Argonne National Laboratory, ANL/ DIS-10-1, 2009. http://www.dis.anl.gov/projects/windpowerforecasting.html.

[22] A. Ozarslan, Large-scale hydrogen energy storage in salt caverns, Int. J. Hydrogen Energy 37 (2012) 14265-14277, http://dx.doi.org/10.1016/j.ijhydene.2012. 07.111 .

[23] P. Pinson, Estimation of the Uncertainty in Wind Power Forecasting, PhD thesis Ecole des Mines de, Paris, 2006.

[24] P. Pinson, H. Madsen, Ensemble-based probabilistic forecasting at horns rev, Wind Energy 12 (2) (2009) 137-155, http://dx.doi.org/10.1002/we.309.

[25] P. Pinson, Adaptive calibration of (u,v) -wind ensemble forecasts, Q. J. R. Meteorol. Soc. 138 (666) (2012) 1273-1284, http://dx.doi.org/10.1002/qj.1873.

[26] A. Shapiro, D. Dentcheva, A. Ruszczynski, Lectures on Stochastic Programming: Modeling and Theory, MPS-SIAM Series on Optimization, SIAM-MPS, Philadelphia, PA, 2009.

[27] A. Shapiro, Monte Carlo sampling methods, in: A. Ruszczynski, A. Shapiro (Eds.), Stochastic Programming, Handbooks in Operations Research and Management Science, Elsevier, 2003.

[28] J. Slaughter, T. Gneiting, A.E. Raftery, Probabilistic wind vector forecasting using ensembles and bayesian model averaging, Mon. Weather Rev. 141 (2013) 2107-2119, http://dx.doi.org/10.1175/MWR-D-12-00002.1.

[29] H. Zhao, Q. Wu, S. Hu, H. Xu, C.N. Rasmussen, Review of energy storage system for wind power integration support, Appl. Energy 137 (2015) 45-53, http:// dx.doi.org/10.1016/j.apenergy.2014.04.103.

[30] S.A. OMI-Polo Español, in: http://www.omie.es/en/inicio, 2016. accessed 10.03.16.

[31] Parque Eólico Experimental SOTAVENTO, 2016. http://www.sotaventogalicia. com/en/technical-area/renewable-facilities/hydrogen-plant. accessed 15.03.16. 